\title{
Pseudo-G-Rh2 induces mitochondrial-mediated apoptosis in SGC-7901 human gastric cancer cells
}

\author{
XIANGRU QU ${ }^{1}$, SHAOCHUN QU $^{1}$, XIAOFENG YU ${ }^{1}$, HUALI XU $^{1}$, \\ YANPING CHEN $^{2}$, XINGYUAN MA ${ }^{2}$ and DAYUAN SUI ${ }^{1}$ \\ ${ }^{1}$ Department of Pharmacology, School of Pharmaceutical Sciences, and ${ }^{2}$ School of \\ Chemistry, Jilin University, Changchun, P.R. China
}

Received May 10, 2011; Accepted June 17, 2011

DOI: $10.3892 /$ or.2011.1442

\begin{abstract}
This study was designed to investigate the effect of pseudo-G-Rh2, a novel metabolite of ginsenoside $\mathrm{Rh} 2$, on the apoptosis of SGC-7901 human gastric cancer cells. PseudoG-Rh2 demonstrated antitumor activity and significantly inhibited the proliferation of SGC-7901 cells in a concentration-dependent manner. After treatment with pseudo-G-Rh2, SGC-7901 cells showed typical apoptotic morphological features, such as chromatin condensation and DNA fragmentation. Pseudo-G-Rh2 could induce mitochondrial membrane potential loss, which led to the release of cytochrome $c$ (Cyt $c$ ), Smac/Diablo and apoptosis-inducing factor (AIF) to the cell cytoplasm. Furthermore, pseudo-G-Rh2 exposure not only decreased the expression of the $\mathrm{Bcl}-2$ protein but also increased the expression of the Bax protein and the activities of caspase- 9 and caspase-3 in SGC-7901 cells. These results demonstrated that pseudo-G-Rh2 inhibited the proliferation of SGC-7901 cells by initiating apoptosis. Pseudo-G-Rh2-induced apoptosis was associated with a drop in the mitochondrial transmembrane potential, down-regulation of Bcl-2, up-regulation of Bax and activation of caspase- 9 and caspase- 3 .
\end{abstract}

\section{Introduction}

Gastric cancer is a leading cause of cancer death worldwide. It causes a significant global health care burden, responsible for approximately 934,000 new diagnoses annually ( $8.6 \%$ of new cancer cases) (1). Globally, gastric cancer is responsible for 700,349 deaths worldwide annually, yielding a case-fatality ratio (CFR) of 0.75 , much higher than other common malignancies, like colon cancer (CFR 0.52), breast cancer (CFR 0.36), or prostate cancer (CFR 0.33) (2). To date, there are only a few

Correspondence to: Dr Dayuan Sui, Department of Pharmacology, School of Pharmaceutical Sciences, Jilin University, Changchun, P.R. China

E-mail: suidayuan@yahoo.com.cn

Key words: pseudo-ginsenoside $\mathrm{Rh} 2$, apoptosis, mitochondrial membrane potential, caspase, SGC-7901 effective clinical treatments for this highly malignant tumor. The progress in treating this disease with chemotherapy over the last 30 years has lagged behind other non-hematologic malignancies, such as breast and colorectal cancer. In this time span, during which the median survival for breast and colorectal cancer has at least doubled $(3,4)$, the median survival for metastatic gastric cancer has increased only marginally, and currently remains at 8-10 months, with an overall 5-year survival of $<7 \%$. Therefore, numerous approaches have been conducted to search for efficient strategies for the development of cancer chemopreventive and chemotherapeutic agents. In recent years, apoptosis has been shown to play a significant role in the elimination of cancer cells (5). Thus, targeting apoptosis pathways in malignant cells may be an effective method of gastric cancer prevention and therapy.

Ginseng, the root of Panax ginseng C.A. Meyer (Araliaceae), has been used as a traditional Chinese medicine due to its wide spectrum of medicinal properties, such as tonic, immunomodulatory, anti-mutagenic, and anti-aging activities (6). Ginsenoside Rh2 is the major effective component of ginseng and has been suggested to have a cell-growth suppressive effect on various cancer cells. It has been reported that ginsenoside Rh2 inhibits cell growth in MCF-7 human breast cancer cells (7) and SK-HEP-1 human hepatoma cells (8). Previous studies demonstrated that ginsenoside Rh2 was also capable of inducing apoptosis in various cells including C6 rat glioma cells (9), SK-N-BE human neuroblastoma cells (10) and A375-S2 human malignant melanoma cells (11).

In most cases, ginseng has been used as an orally administered crude drug. It has been reported that ginsenosides are metabolized by intestinal bacterial and the intestinal bacterial metabolites were responsible for the main pharmacological activities of ginseng (12-14). However, the intestinal bacteria are liable to be influenced by a human's makeup and his dietary patterns. Thus, any individual differences in the metabolism of ginseng may lead to individual differences in his treatment.

Recently, the structure of a novel metabolite designated as pseudo-G-Rh2 with the chemical name of $3-O-\beta-D$ glucopyranosyl-3 $\beta, 12 \beta, 25$-trihydroxyl dammar-20(22)-ene in rat plasma after oral administration of ginsenoside $\mathrm{Rh} 2$ has been described (Fig. 1). In a study in vitro, ginsenoside Rh2 was degraded into pseudo-G-Rh2 by Professor Chen at the College of Chemistry, Jilin University. It was thus of interest 
to elucidate whether pseudo-G-Rh2 has antitumor effects in human tumor cell lines. In the present study, the growth inhibition and induction of apoptosis by pseudo-G-Rh2 in human gastric cancer SGC-7901 cells were investigated.

\section{Materials and methods}

Chemicals and reagents. Purified pseudo-G-Rh2 (purity $>98 \%$ ) was generously provided by Professor Chen, College of Chemistry, Jilin University. Dimethyl sulfoxide (DMSO) and (4,5-dimethylthiazol-2-yl)-2,5-diphenyltetrazo-lium bromide (MTT) were purchased from Sigma (St. Louis, MO, USA). Hoechst 33342, caspase-3, and caspase-9 activity assay kits were from Beyotime Institute of Biotechnology (Shanghai, China). Annexin V-FITC/PI apoptosis assay kits were obtained from KeyGEN Biotechnology (Nanjing, China). Rabbit polyclonal antibodies specific to Bax, Bcl-2, Cyt $c$, Smac/Diablo, AIF, and goat anti-rabbit secondary antibodies were bought from Santa Cruz Biotechnology (Santa Cruz, CA). RPMI-1640 medium and fetal calf serum were purchased from Northern Biotech Institute (Beijing, China).

Cell lines and cell culture. Human gastric cancer SGC-7901 cells were purchased from the Shanghai Institute of Cell Biology, Chinese Academy of Sciences. SGC-7901 cells of a suitable concentration were inoculated in culture flasks containing RPMI-1640 solution with $10 \%$ fetal bovine serum, $100 \mathrm{U} / \mathrm{ml}$ penicillin and $100 \mu \mathrm{g} / \mathrm{ml}$ streptomycin at $37^{\circ} \mathrm{C}$ in a humidified incubator with $5 \% \mathrm{CO}_{2}$.

Cell growth and viability assay. The effect of pseudo-G-Rh2 on the viability of cells was determined by the MTT assay. Briefly, SGC-7901 cells were plated at $5 \times 10^{4}$ cells/well with $200 \mu 1$ of complete culture medium in 96-well microtiter plates. After incubating for $24 \mathrm{~h}$, cells were treated with 5,10 , 20,40 and $80 \mu \mathrm{g} / \mathrm{ml}$ of pseudo-G-Rh2 for another $24 \mathrm{~h}$. The cell viability was determined by adding $10 \mu 1$ MTT $(5 \mathrm{mg} / \mathrm{ml}$ in phosphate-buffered saline) to each well followed by incubation for $4 \mathrm{~h}$. After careful removal of the medium, $200 \mu \mathrm{l}$ DMSO was added to each well and shaken carefully. The absorbance was recorded on a Microplate Reader (SpectraMax ${ }^{\circledR}$ Plus384, Molecular Devices, USA) at a wavelength of $570 \mathrm{~nm}$. Percentage of survival was calculated as a fraction of the negative control (medium only).

Hoechst 33342 staining for morphological evaluation. Chromatin condensation was detected by nuclear staining with Hoechst 33342 as previously described with a minor modification (15). SGC-7901 cells were incubated with or without pseudo-G-Rh2 for $24 \mathrm{~h}$. The cells were subsequently washed with phosphate-buffered saline (PBS) and fixed in $4 \%$ formaldehyde at $4^{\circ} \mathrm{C}$ for $10 \mathrm{~min}$ and then washed again with PBS. The fixed cells were incubated with Hoechst $33342(60 \mu \mathrm{g} / \mathrm{ml})$ for $15 \mathrm{~min}$ at room temperature in the dark. Morphological changes of the pseudo-G-Rh2-treated cells were examined using a Nikon TE-2000U fluorescence microscope (Tokyo, Japan).

Annexin V-FITC/propidium iodide assay for the analysis of apoptotic cells. After treatment with pseudo-G-Rh2 for $24 \mathrm{~h}$,

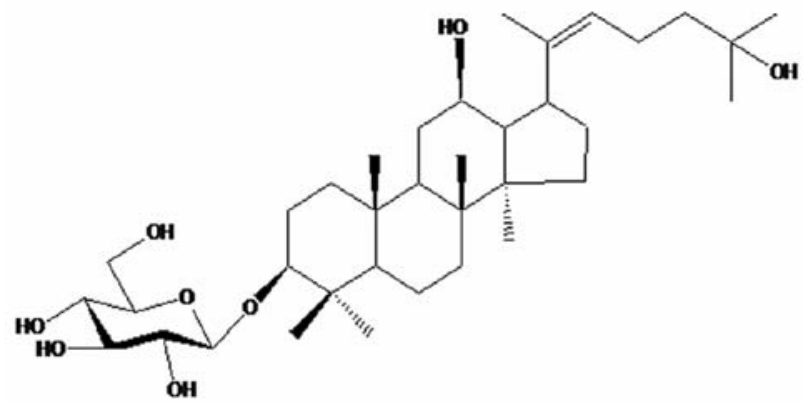

Figure 1. Structure of pseudo-G-Rh2.

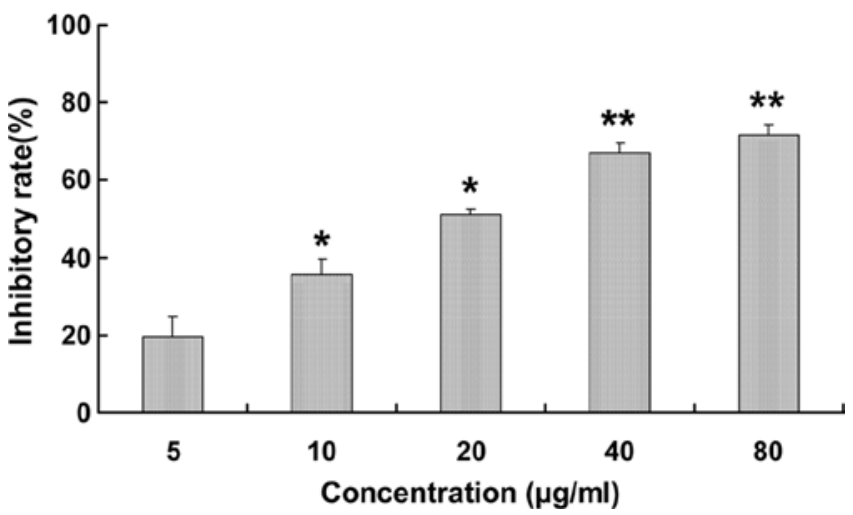

Figure 2. Effects of pseudo-G-Rh2 on the cell viability in human gastric cancer SGC-7901 cells. SGC-7901 cells were plated at 5x104 cells/ well in 96-well microtiter plates. The cell inhibition rate was determined by the MTT assay after treatment with different concentrations of pseudo-G-Rh2 for $24 \mathrm{~h}$. Concentration-dependent inhibition of SGC-7901 cell growth was observed. Data are expressed as the means $\pm \mathrm{SD} ;{ }^{*} \mathrm{p}<0.05,{ }^{* *} \mathrm{p}<0.01$ compared to untreated group.

SGC-7901 cells were collected and washed twice in cold PBS and resuspended in $300 \mu \mathrm{l}$ of binding buffer at $1 \times 10^{6}$ cells $/ \mathrm{ml}$. The samples were incubated with $5 \mu \mathrm{l}$ of Annexin V-FITC and $5 \mu \mathrm{l}$ propidium iodide (PI) in the dark for $15 \mathrm{~min}$ at room temperature. Finally, samples were analyzed by a flow cytometer (FACScalibur, BD Biosciences) and evaluated based on the percentage of cells that were Annexin V-positive.

Detection of mitochondrial membrane potential. Mitochondrial membrane potential was measured by using rhodamine 123 . Briefly, SGC-7901 cells were treated with pseudo-G-Rh2 under a concentration of 10,20 and $40 \mu \mathrm{g} / \mathrm{ml}$ for $24 \mathrm{~h}$. Then the cells were incubated with rhodamine $123(10 \mu \mathrm{g} / \mathrm{ml})$ at $37^{\circ} \mathrm{C}$ for $30 \mathrm{~min}$ and washed with PBS. The cell pellet was collected by centrifugation $(500 \times \mathrm{g}, 5 \mathrm{~min})$ and resuspended in $300 \mu \mathrm{l}$ of PBS. Fluorescence intensities of rhodamine 123 in cells were analyzed by flow cytometric analysis.

Western blot analysis of Cyt c, Smac/Diablo, AIF, Bcl-2, and $B a x$. SGC-7901 cells were seeded in 6-well plates. After treatment with pseudo-G-Rh2 for $24 \mathrm{~h}$, the cells were harvested and lysed in RIPA buffer $(150 \mathrm{mM} \mathrm{NaCl}, 1 \%$ Triton X-100, $0.5 \%$ sodium deoxycholate, $0.1 \% \mathrm{SDS}, 50 \mathrm{mM}$ Tris- $\mathrm{HCl}$, $\mathrm{pH}$ 7.4) for $30 \mathrm{~min}$ on ice. After centrifugation $(12,000 \mathrm{x} \mathrm{g}$ at $4^{\circ} \mathrm{C}$ for $15 \mathrm{~min}$ ), the supernatants were loaded onto poly- 

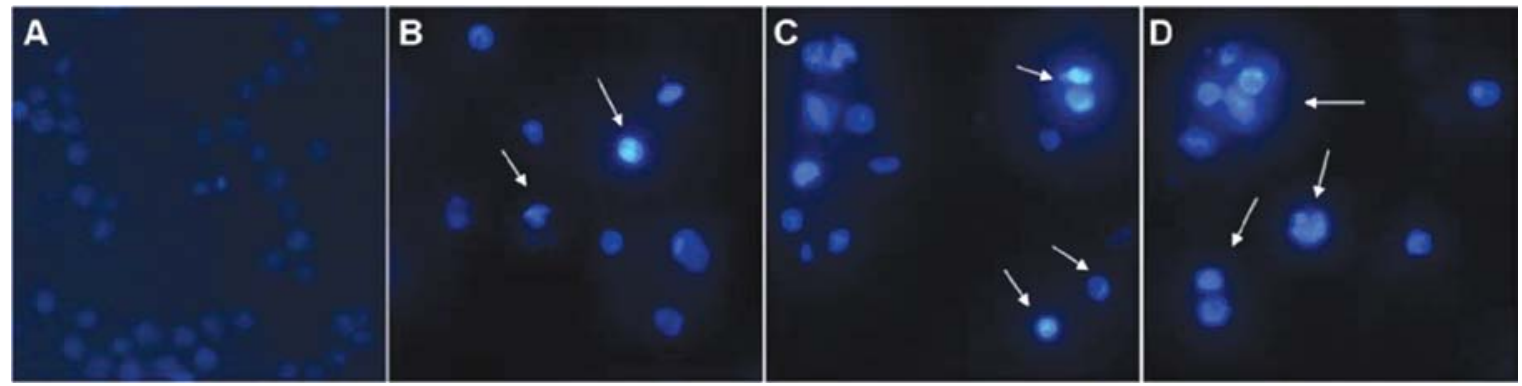

Figure 3. Effects of pseudo-G-Rh2 on the morphology of SGC-7901 cells. Cells were treated with different concentrations of pseudo-G-Rh2 for $24 \mathrm{~h}$. Morphological changes of nuclear chromatin were detected by nuclear staining with Hoechst 33342. The arrows indicate apoptotic cells. The apoptotic nuclei were not observed in untreated (medium only) cells (A). In contrast, the SGC-7901 cells treated with pseudo-G-Rh2 for $24 \mathrm{~h}$ displayed fewer intercellular connections and exhibited typical apoptotic morphology. Cells were treated with (B) $10 \mu \mathrm{g} / \mathrm{ml}$, (C) $20 \mu \mathrm{g} / \mathrm{ml}$, and (D) $40 \mu \mathrm{g} / \mathrm{ml}$ of pseudo-G-Rh2 .

A

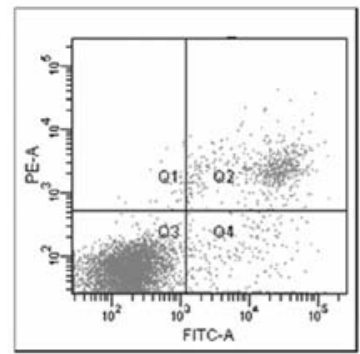

B

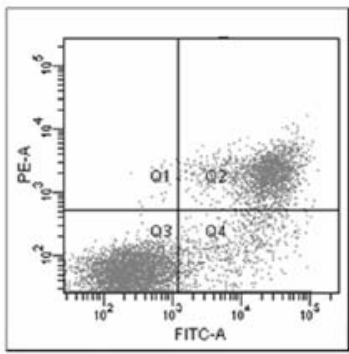

C

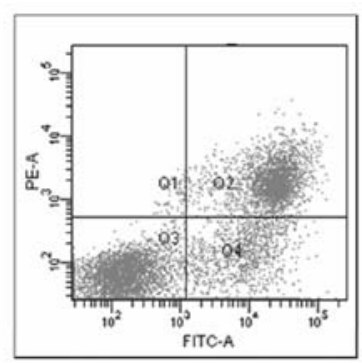

D

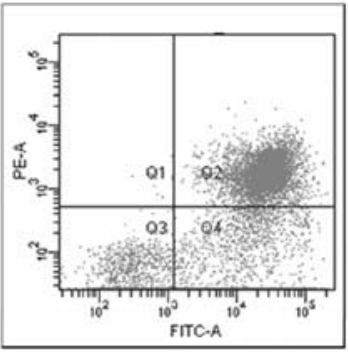

Figure 4. Apoptotic cells detected by flow cytometry with Annexin V-FITC/PI staining. SGC-7901 cells were treated with (A) medium only or pseudo-G-Rh2 at (B) $10 \mu \mathrm{g} / \mathrm{ml}$, (C) $20 \mu \mathrm{g} / \mathrm{ml}$, or (D) $40 \mu \mathrm{g} / \mathrm{ml}$.

acrylamide SDS gels. Each lane was loaded with $40 \mu \mathrm{g}$ of cell lysate protein. After electrophoresis, the gels were blotted onto a PVDF membrane, blocked with $5 \%(\mathrm{w} / \mathrm{v})$ milk for $1 \mathrm{~h}$ on a shaker at room temperature, washed twice with TBS-T, and then probed overnight at $4^{\circ} \mathrm{C}$. Primary antibody binding was detected with anti-rabbit IgG conjugated to HRP, and visualized by ECL-enhanced chemiluminescence.

Caspase-3 and caspase-9 activity assays. The activities of caspase- 3 and caspase- 9 were determined using the kits according to the manufacturer's protocol. After exposure to pseudo-G-Rh2 for $24 \mathrm{~h}, \mathrm{SGC}-7901$ cells were collected and rinsed with cold PBS. Cell lysates were prepared in lysis buffer (100 $\mu \mathrm{l}$ ) for $15 \mathrm{~min}$ on ice and centrifuged at 16,000 $\mathrm{x} \mathrm{g}$ for $15 \mathrm{~min}$ at $4^{\circ} \mathrm{C}$. The supernatants were collected and the total protein was quantified by the Bradford method. Assays were performed on 96-well microtiter plates by incubating $20 \mu \mathrm{l}$ protein of cell lysate per sample in $80 \mu \mathrm{l}$ reaction buffer $(1 \%$ NP-40, $20 \mathrm{mM}$ Tris-HCl, $137 \mathrm{mM}$ NAD and 10\% glycerol) containing $10 \mu \mathrm{l}$ caspase-3 substrate (Ac-DEVD-pNA) and $10 \mu 1$ caspase-9 substrate (Ac-LEHD-pNA). Lysates were incubated at $37^{\circ} \mathrm{C}$ for $2 \mathrm{~h}$ and were measured with a microplate reader at an absorbance of $405 \mathrm{~nm}$. Results are presented as the percentage of change of activity compared to the untreated control.

Statistical analysis. Differences among groups were analyzed by one-way analysis of variance (ANOVA) followed by the Student's t-test. Data are expressed as the means \pm SD and $\mathrm{p}<0.05$ was considered statistically significant.

\section{Results}

Effects of pseudo-G-Rh2 on the proliferation of SGC-7901 cells. The anti-proliferative effect of pseudo-G-Rh2 on SGC-7901 cells was examined by treating cells with different concentrations of pseudo-G-Rh2 $(5,10,20,40,80 \mu \mathrm{g} / \mathrm{ml})$ for $24 \mathrm{~h}$. The results showed that pseudo-G-Rh2 inhibited the proliferation of SGC-7901 cells in a concentration-dependent manner $(\mathrm{p}<0.05$ or $\mathrm{p}<0.01$ ). The $\mathrm{IC}_{50}$ value of pseudo-G-Rh2 for inhibition of SGC-7901 cell proliferation was $32.9 \mu \mathrm{g} / \mathrm{ml}$ (Fig. 2).

Effects of pseudo-G-Rh2 on morphological apoptosis in SGC-7901 cells. Morphological evaluation revealed slight Hoechst 33342 nuclear staining in untreated (medium only) cells, and apoptotic nuclei were not observed. In contrast, treatment with pseudo-G-Rh2 for $24 \mathrm{~h}$ significantly altered SGC-7901 cell morphology, and most of the pseudo-GRh2-exposed cells were shrunken and detached from the substratum of the culture dish. Hoechst-stained SGC-7901 cells displayed fewer intercellular connections and exhibited typical apoptotic morphology characterized by chromatin condensation and DNA fragmentation (Fig. 3). In order to quantitate the apoptosis, phosphatidylserine externalization onto the cell surface was examined by Annexin V-FITC/ PI staining. As shown in Fig. 4, the percentage of Annexin V-FITC stained early and late apoptotic cells increased with the treatment of pseudo-G-Rh2 for $24 \mathrm{~h}$.

Effects of pseudo-G-Rh2 on mitochondrial transmembrane potential in SGC-7901 cells. Mitochondria play an essential 
A

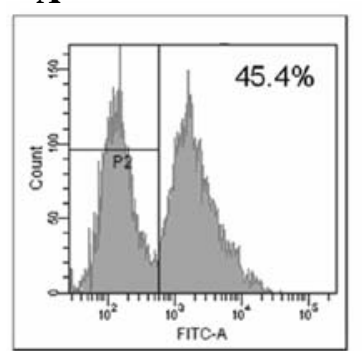

B

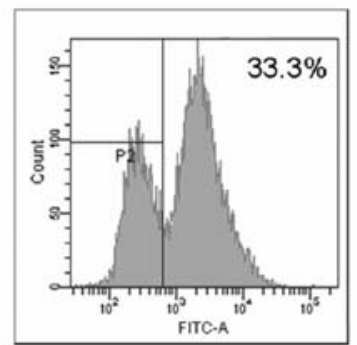

C

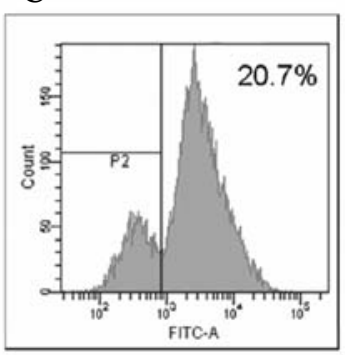

D

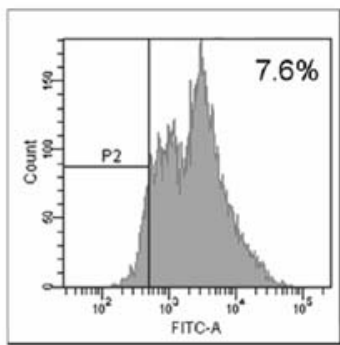

Figure 5. Effects of pseudo-G-Rh2 on the mitochondrial membrane potential in SGC-7901 cells. SGC-7901 cells were treated with different concentrations of pseudo-G-Rh2 for $24 \mathrm{~h}$. The mitochondrial membrane potential was analyzed by flow cytometry with fluorescent rhodamine 123 dye staining. (A) Medium only, (B) $10 \mu \mathrm{g} / \mathrm{ml}$, (C) $20 \mu \mathrm{g} / \mathrm{ml}$, and (D) $40 \mu \mathrm{g} / \mathrm{ml}$ of pseudo-G-Rh2.

A
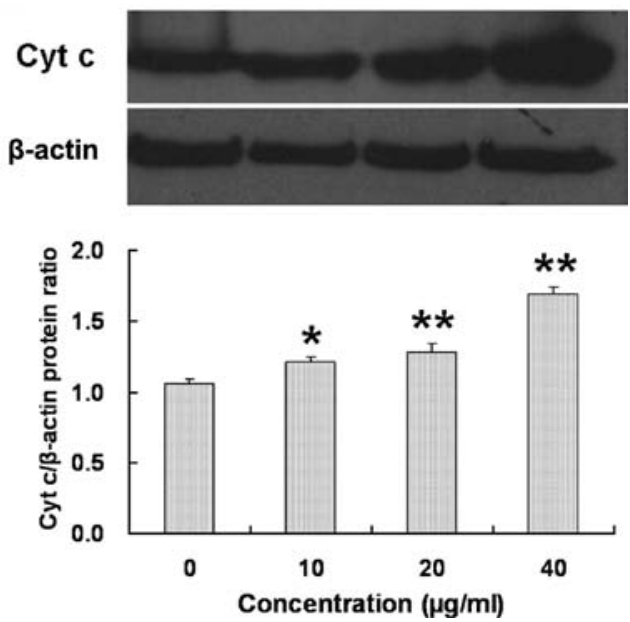

C
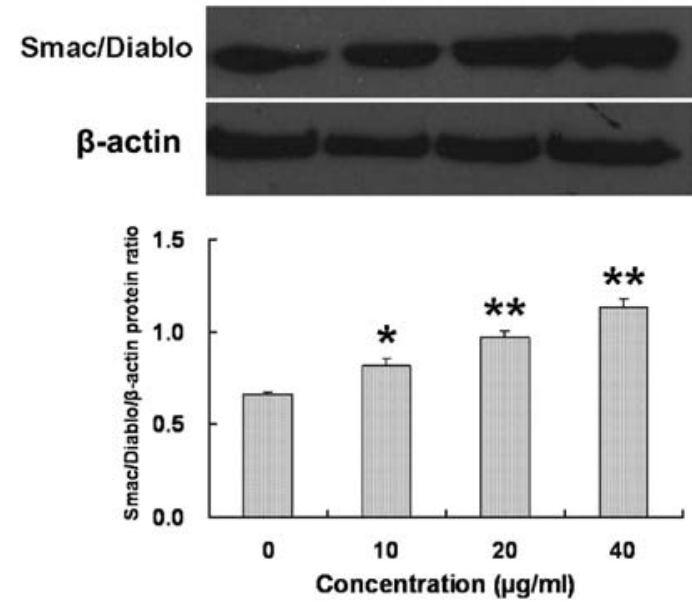

role in the progression of apoptosis, and the disruption of the mitochondrial membrane potential is a critical step occurring in cells undergoing apoptosis. The mitochondrial transmembrane potentials in SGC-7901 cells exposed to 10, 20 and $40 \mu \mathrm{g} / \mathrm{ml}$ of pseudo-G-Rh2 for $24 \mathrm{~h}$ were significantly lower than that of the control group $(33.3 \pm 2.4,20.7 \pm 1.4,7.6 \pm 0.6 \%$ vs. $45.4 \pm 1.1 \%, \mathrm{p}<0.05$ or $\mathrm{p}<0.01)$. It was also shown that pseudoG-Rh2 decreased the mitochondrial transmembrane potentials in a concentration-dependent manner (Fig. 5).

Effects of pseudo-G-Rh2 on the contents of Cyt c, Smac/Diablo, and AIF in SGC-7901 cells. Cyt $c$, Smac/Diablo, and AIF release from mitochondria is essential for programmed cell death. Compared to the control, the contents of Cyt $c$, Smac/
B
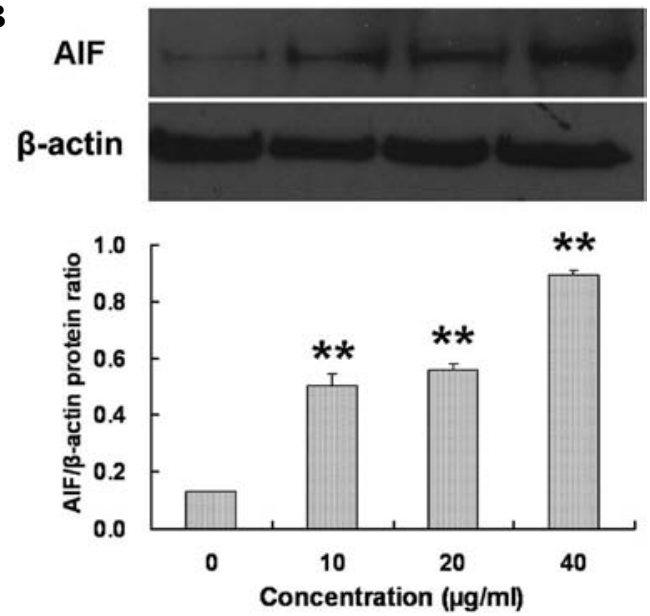

Figure 6. Western blot analysis of Cyt $c$, Smac/Diablo, and AIF protein expression in SGC-7901 cells treated with or without pseudo-G-Rh2 for $24 \mathrm{~h}$. SDS-PAGE was performed and the proteins were transferred to PVDF membranes and detected by anti-Cyt $c$, anti-Smac/Diablo, and anti-AIF antibodies. Relative expression of Cyt $c$, Smac/Diablo, and AIF protein are expressed as a percentage of $\beta$-actin. (A) Cyt $c$ protein, (B) AIF protein, (C) Smac/Diablo protein. Data are expressed as the means $\pm \mathrm{SD}$; ${ }^{\mathrm{p}}<0.05$, ${ }^{* *} \mathrm{p}<0.01$ compared to untreated group.

Diablo, and AIF were significantly increased after exposure to any concentration of pseudo-G-Rh2 (10,20 and $40 \mu \mathrm{g} / \mathrm{ml})$, $(\mathrm{p}<0.05)$ (Fig. 6).

Effects of pseudo-G-Rh2 on the expression of Bcl-2 family proteins in SGC-7901 cells. After pseudo-G-Rh2 (10, 20 and $40 \mu \mathrm{g} / \mathrm{ml}$ ) exposure, the expression of the Bcl-2 protein was significantly lower, while the expression of the Bax protein was significantly higher than that in the control group $(\mathrm{p}<0.05$ or $\mathrm{p}<0.01)$ (Fig. 7).

Effects of pseudo-G-Rh2 on caspase-3 and caspase-9 activities in SGC-7901 cells. Caspases, a family of cysteine proteases, is known to form integral parts of the apoptotic pathway. The 
A
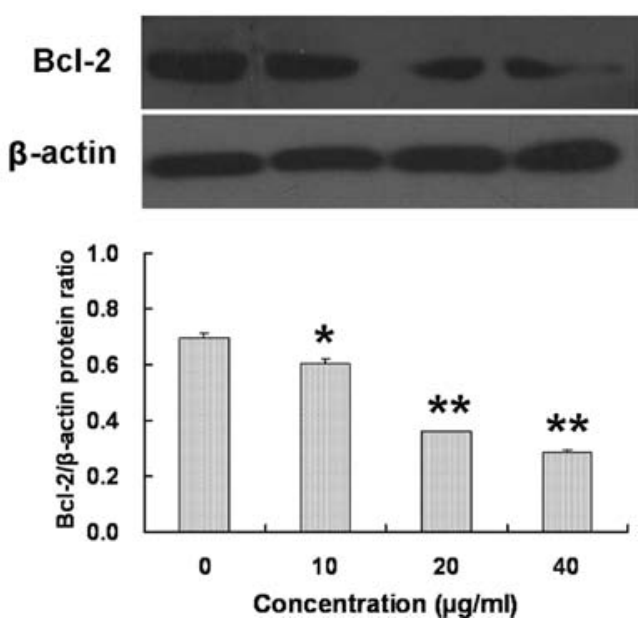

B
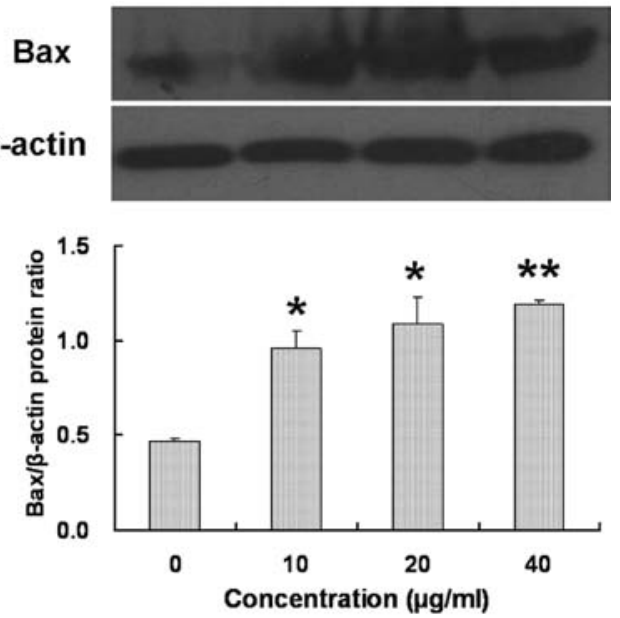

Figure 7. Western blot analysis of (A) Bcl-2 and (B) Bax protein expression in SGC-7901 cells treated with or without pseudo-G-Rh2 for 24 h. SDS-PAGE was performed and the proteins were transferred to PVDF membranes and detected by anti-Bcl-2 and anti-Bax antibodies. Relative expression of Bcl-2 and Bax protein are expressed as a percentage of $\beta$-actin. Data are expressed as the means $\pm \mathrm{SD} ;{ }^{*} \mathrm{p}<0.05,{ }^{* *} \mathrm{p}<0.01$ compared to untreated group.

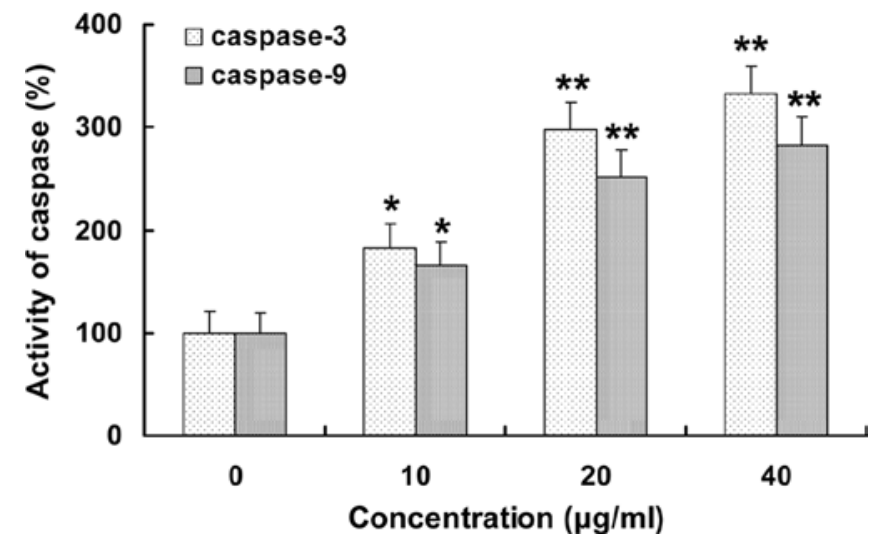

Figure 8. Effects of pseudo-G-Rh2 on the activities of caspase-3 and caspase- 9 in SGC-7901 cells. SGC-7901 cells were treated with different concentrations of pseudo-G-Rh2 for $24 \mathrm{~h}$. The activities of caspase-3 and caspase- 9 were measured using the substrate Ac-DEVD-pNA and Ac-LEHD-pNA. Relative caspase-3 and caspase-9 activities were calculated as a ratio of treated cells to untreated cells. Data are expressed as the means $\pm \mathrm{SD} ;{ }^{*} \mathrm{p}<0.05,{ }^{* *} \mathrm{p}<0.01$ compared to untreated group.

activities of caspase- 9 and caspase- 3 were detected by spectrophotometry. The activities of caspase- 3 and caspase- 9 were significantly increased after exposure to pseudo-G-Rh2 (10, 20 and $40 \mu \mathrm{g} / \mathrm{ml})(\mathrm{p}<0.05$ or $\mathrm{p}<0.01)$ (Fig. 8). It was also shown that pseudo-G-Rh2 increased the activities of caspase-3 and caspase- 9 in a concentration-dependent manner.

\section{Discussion}

Gastric cancer is one of the most common malignancies in the world, particularly in Eastern Asian countries such as China, Korea, and Japan (16), and it is characterized by its high capacity for proliferation (17). In this study, SGC-7901 cells were treated with pseudo-G-Rh2 at different concentrations from 5 to $80 \mu \mathrm{g} / \mathrm{ml}$ for $24 \mathrm{~h}$. The results showed that pseudoG-Rh2, a novel metabolite of ginsenoside Rh2, was able to significantly inhibit the proliferation of the SGC-7901 cell line in a concentration-dependent manner.
Apoptosis, or programmed cell death, is a major control mechanism by which cells die if DNA damage is not repaired. Apoptosis is important in controlling cell number and proliferation as part of normal development. It is also essential for the elimination of cancer cells (18). The present experiment showed that the proliferation inhibition of SGC-7901 was the result of apoptosis induction, as evidenced by the cell morphological analyses of the pseudo-G-Rh2-treated SGC-7901 cells showing the apoptotic characteristics, such as appearance of apoptotic bodies, nuclear shrinkage and condensed chromatin when compared to control cells. Flow cytometry data of Annexin V-FITC/ PI staining confirmed that pseudo-G-Rh2 could alter the apoptotic ratio in a concentration-dependent manner. Flow cytometry was used to investigate the loss of mitochondrial membrane potential which had been shown to play an essential role in mediating apoptosis (19). Rhodamine 123-staining experiments showed that the mitochondrial transmembrane potentials in SGC-7901 cells decreased after pseudo-G-Rh2 exposure, which indicated that the mitochondrial apoptotic death-signaling pathway plays a critical role in pseudo-GRh2-induced apoptosis in SGC-7901 cells.

There are two major mechanisms of cell death-necrosis and apoptosis. Cells that are damaged by external injury undergo necrosis, while cells that are induced to commit programmed suicide because of internal or external stimuli undergo apoptosis. Stimulation of the intrinsic or mitochondrial pathway leads to the release of Cyt $c$, Smac/Diablo, and AIF from the mitochondria and activation of the death signal (20). In healthy cells, Cyt $c$ exists in the mitochondrial intermembrane space where it acts in the electron transport chain to transfer electrons from complex III to complex IV. In the cytoplasm of cells undergoing apoptosis, Cyt $c$ binds to Apaf-1, and then triggers formation of the apoptosome. It has been reported that the presence of Cyt $c$ in the cytosol is sufficient to cause caspase-dependent cell death (21). A previous study has shown that Smac/Diablo could enhance activation of caspase-3 in vitro, and found that, like Cyt $c, \mathrm{Smac} /$ Diablo is a mitochondrial protein released into the cytosol of cells undergoing apoptosis (22). AIF is a mitochondrial 
cysteine protease which translocates from the mitochondria to the nucleus resulting in DNA fragmentation and cell death following an apoptotic stimulus. Moreover, it has been claimed that AIF is essential for programmed cell death, and that in the nucleus it directly binds DNA (23). One of the most important regulators of the mitochondria-mediated apoptosis is the $\mathrm{Bcl}-2$ family of proteins. The $\mathrm{Bcl}-2$ family includes the pro-apoptotic members, such as Bax, Bak, and Bad, and the anti-apoptotic members, such as Bcl-2 and Bcl- $\mathrm{x}_{\mathrm{L}}$. Bax could breach mitochondrial integrity, provoke the permeabilization of the outer mitochondrial membrane and dissipate mitochondrial membrane potential, allowing the efflux of mitochondrial proteins, such as Cyt $c$, Smac/Diablo and AIF. Anti-apoptotic Bcl-2 members act as repressors of apoptosis by blocking the release of mitochondrial proteins (24). In the present study, treatment with pseudo-G-Rh2 not only reduced the expression of Bcl-2, but also increased the expression of Bax. It was also found that pseudo-G-Rh2 exposure increased the contents of Cyt $c$, Smac/Diablo and AIF in SGC-7901 cells. All these findings indicate that apoptosis of SGC-7901 cells induced by pseudo-G-Rh2 is related to the up-regulation of Bax with a concomitant down-regulation of Bcl-2 levels followed by an increase of the contents of Cyt $c$, Smac/Diablo and AIF.

Caspases, a family of cysteine-dependent aspartate-directed proteases, play critical roles in the initiation and execution of apoptosis (25). Caspases are synthesized as pro-enzymes and undergo proteolytic activation during apoptosis. The mitochondrial pathway requires the release of mitochondrial Cyt $c$, Smac/Diablo, and AIF and the formation of a large multiprotein complex comprising Cyt $c$, Apaf-1 and procaspase-9. Caspase-9 will then proteolytically activate downstream caspases, in particular caspases-3 which is responsible for the apoptotic destruction of the cell. The results of this study showed that pseudo-G-Rh2 exposure caused the activation of caspase- 9 and caspase- 3 in a concentration-dependent manner. Hence, we presumed that pseudo-G-Rh2 regulated the expression of Bcl-2 family proteins and increased the release of Cyt $c$, Smac/ Diablo, and AIF, which then led to the activation of caspase-9 and caspase-3 to induce the apoptosis of SGC-7901 cells.

In conclusion, the current report demonstrated for the first time that pseudo-G-Rh2 induced growth inhibition in SGC-7901 cells by apoptosis initiation. Pseudo-G-Rh2induced apoptosis was closely associated with a drop in the mitochondrial transmembrane potential, down-regulation of Bcl-2, up-regulation of Bax and activation of caspase- 9 and caspase-3. Nevertheless, further detailed studies are required to clarify the cellular signaling process by which pseudo-G$\mathrm{Rh} 2$ induces apoptosis in SGC-7901 cell.

\section{Acknowledgements}

The authors wish to thank Yanping Chen and Zhibo Yu at the college of chemistry, Jilin University for providing pseudo-G$\mathrm{Rh} 2$.

\section{References}

1. Zhang W, Ha M, Gong Y, Xu Y, Dong N and Yuan Y: Allicin induces apoptosis in gastric cancer cells through activation of both extrinsic and intrinsic pathways. Oncol Rep 24: 1585-1592, 2010.
2. Parkin DM, Bray F, Ferlay J and Pisani P: Global cancer statistics, 2002. CA Cancer J Clin 55: 74-108, 2005.

3. Colozza M, de Azambuja E, Personeni N, Lebrun F, Piccart MJ and Cardoso F: Achievements in systemic therapies in the pregenomic era in metastatic breast cancer. Oncologist 12: 253-270, 2007.

4. Kopetz S, Chang GJ, Overman MJ, et al: Improved survival in metastatic colorectal cancer is associated with adoption of hepatic resection and improved chemotherapy. J Clin Oncol 27: 3677-3683, 2009.

5. Ghobrial IM, Witzig TE and Adjei AA: Targeting apoptosis pathways in cancer therapy. CA Cancer J Clin 55: 178-194, 2005.

6. Kiefer D and Pantuso T: Panax ginseng. Am Fam Physician 68: 1539-1542, 2003.

7. Oh M, Choi YH, Choi S, et al: Anti-proliferating effects of ginsenoside Rh2 on MCF-7 human breast cancer cells. Int J Oncol 14: 869-875, 1999.

8. Lee KY, Park JA, Chung E, Lee YH, Kim SI and Lee SK: Ginsenoside-Rh2 blocks the cell cycle of SK-HEP-1 cells at the G1/S boundary by selectively inducing the protein expression of p27kip1. Cancer Lett 110: 193-200, 1996.

9. Kim HE, Oh JH, Lee SK and Oh YJ: Ginsenoside RH-2 induces apoptotic cell death in rat C6 glioma via a reactive oxygen- and caspase-dependent but Bcl-X(L)-independent pathway. Life Sci 65: 33-40, 1999.

10. Kim YS, Jin SH, Lee YH, Park JD and Kim SI: Differential expression of protein kinase $\mathrm{C}$ subtypes during ginsenoside Rh2-Induced apoptosis in SK-N-BE(2) and C6Bu-1 cells. Arch Pharm Res 23: 518-524, 2000.

11. Fei XF, Wang BX, Tashiro S, Li TJ, Ma JS and Ikejima T: Apoptotic effects of ginsenoside Rh2 on human malignant melanoma A375-S2 cells. Acta Pharmacol Sin 23: 315-322, 2002.

12. Hasegawa H, Sung JH, Matsumiya S and Uchiyama M: Main ginseng saponin metabolites formed by intestinal bacteria. Planta Med 62: 453-457, 1996.

13. Lee SJ, Sung JH, Lee SJ, Moon CK and Lee BH: Antitumor activity of a novel ginseng saponin metabolite in human pulmonary adenocarcinoma cells resistant to cisplatin. Cancer Lett 144: 39-43, 1999.

14. Atopkina LN, Malinovskaya GV, Elyakov GB, et al: Cytotoxicity of natural ginseng glycosides and semisynthetic analogues. Planta Med 65: 30-34, 1999.

15. Porn-Ares MI, Chow SC, Slotte JP and Orrenius S: Induction of apoptosis and potentiation of TNF- and Fas-mediated apoptosis in U937 cells by the xanthogenate compound D609. Exp Cell Res 235: 48-54, 1997.

16. Alberts SR, Cervantes A and van de Velde CJ: Gastric cancer: epidemiology, pathology and treatment. Ann Oncol 14 (Suppl 2): 31-36, 2003.

17. Tahara E: Molecular aspects of invasion and metastasis of stomach cancer. Verh Dtsch Ges Pathol 84: 43-49, 2000.

18. Vaux DL and Korsmeyer SJ: Cell death in development. Cell 96: 245-254, 1999.

19. Desagher S and Martinou JC: Mitochondria as the central control point of apoptosis. Trends Cell Biol 10: 369-377, 2000.

20. Reed JC: Apoptosis-regulating proteins as targets for drug discovery. Trends Mol Med 7: 314-319, 2001.

21. Acehan D, Jiang X, Morgan DG, Heuser JE, Wang $X$ and Akey CW: Three-dimensional structure of the apoptosome: implications for assembly, procaspase- 9 binding, and activation. Mol Cell 9: 423-432, 2002.

22. Du C, Fang M, Li Y, Li L and Wang X: Smac/Diablo, a mitochondrial protein that promotes cytochrome c-dependent caspase activation by eliminating IAP inhibition. Cell 102: 33-42, 2000.

23. Joza N, Susin SA, Daugas E, et al: Essential role of the mitochondrial apoptosis-inducing factor in programmed cell death. Nature 410: 549-554, 2001.

24. Reed JC: Bcl-2 and the regulation of programmed cell death. J Cell Biol 124: 1-6, 1994.

25. Budihardjo I, Oliver H,Lutter M, Luo X and Wang X: Biochemical pathways of caspase activation during apoptosis. Annu Rev Cell Dev Biol 15: 269-290, 1999. 